\title{
Article
}

\section{Resilience and the (Micro-)Dynamics of Organizational Ambidexterity: Implications for Strategic HRM}

Stokes, Peter, Smith, Simon, Wall, Tony, Moore, Neil, Rowland, Caroline, Ward, Tony and Cronshaw, Sue

Available at http://clok.uclan.ac.uk/23250/

Stokes, Peter, Smith, Simon, Wall, Tony, Moore, Neil, Rowland, Caroline, Ward, Tony and Cronshaw, Sue (2019) Resilience and the (Micro-)Dynamics of Organizational Ambidexterity: Implications for Strategic HRM. The International Journal of Human Resource Management, 30 (8). pp. 1287-1322. ISSN 0958-5192

It is advisable to refer to the publisher's version if you intend to cite from the work. http://dx.doi.org/10.1080/09585192.2018.1474939

For more information about UCLan's research in this area go to http://www.uclan.ac.uk/researchgroups/ and search for <name of research Group>.

For information about Research generally at UCLan please go to http://www.uclan.ac.uk/research/

All outputs in CLoK are protected by Intellectual Property Rights law, including Copyright law. Copyright, IPR and Moral Rights for the works on this site are retained by the individual authors and/or other copyright owners. Terms and conditions for use of this material are defined in the policies page.

\section{CLoK}

Central Lancashire online Knowledge www.clok.uclan.ac.uk

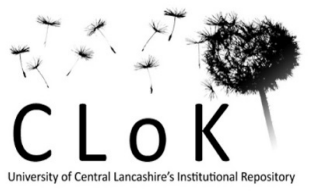




\title{
Resilience and the (Micro-)Dynamics of Organizational Ambidexterity: Implications for Strategic HRM
}

\begin{abstract}
In the twenty-first century, resilience has emerged as an important topic linked to calls for adaptability, well-being and organizational performance. Extant strategic human resource management (HRM) literature and practices have developed many insights into resilience. However, overall, they have a propensity to conceptualise resilience as being associated with 'macro-' and 'extreme' situations. This paper complements the prevailing perspective by developing a micro-focus on resilience through the conceptual framework of organizational ambidexterity surfacing under-examined individual resilience in connection with HRM practices.

Methodologically, the paper adopts a qualitative approach presenting data from two illustrative contexts: an 'everyday' quasi-governmental institution and a prima facie 'extreme' pan-international military organization. Using template analysis, a number of valuable themes and similarities are identified. The findings and discussion underline the managerial challenges in handling organizational ambidextrous dynamics and tensions surrounding resilience, positive and sceptical approaches in relation to individual and organizational stances towards HRM practices. As such, the results point at value in HRM managers and practices recontextualising and appreciating 'extremes' and resilience more as an everyday (rather than exceptional) phenomenon wherein myriad micro-moments are highly significant in constructing and influencing macro-contexts. This also implies a need to see cynical resistance as normative rather than automatically negatively.
\end{abstract}

Key words: Resilience, Organizational Ambidexterity, Extremes, HRM practices, micromoments

\section{Introduction}

Resilience, which is generally understood as the capacity to endure and withstand challenges through the cultivation of individual, team and organizational capacities, has become an important and prevalent organizational issue in the twenty-first century (Luthans, 2002; Kostopoulos \& Bozionelos, 2011; Bardoel et al., 2014; Branicki, Steyer \& Sullivan-Taylor, 2016; Kossek \& Perrigino, 2016). Much of the extant work on resilience and HRM practices has tended to consider how teams and organizations identify, develop and employ resilience in order to manage testing situations whilst assuring the maintenance of, for instance, wellbeing, performance and effectiveness among employees (Hitt \& Ireland, 2002; Gittell, Seidner \& Wimbush, 2010; Wood \& de Menezes, 2011; Biron \& Bamberger, 2011; Southwick et al, 2014; Hu, Zhang \& Wang 2015; Edgar, 2015). Thus, it is evident that resilience, among other key issues, remains an ongoing important topic for strategic human 
resource management (HRM) practices (Lepak \& Shaw, 2008; Kaufman, 2012). Overall, considerable progress and contributions have been made in relation to understanding resilience and HRM practices across a number of diverse domains including, for example: the role of gender (Huang, Xing, \& Gamble, 2016); impact of technological capabilities (Bustinza et al., 2016); policing (Papazoglou \& Andersen, 2014); psychological contracts in voluntary organizations (Cunningham, 2010); and, the development of organizational capacity (Lengnick-Hall, Beck and Lengnick-Hall, 2011). However, this existing work has also had a propensity to see resilience as being linked primarily to (macro-) extreme situations i.e.: crises, dilemmas and dramatic events. Nevertheless, in addition, there exists scope to view resilience and 'extremes' as also residing in more 'everyday' (rather than mainly exceptional and extraordinary, macro-type) contexts and HRM practices. The present paper argues that a reconceptualization of the dynamics surrounding resilience and HRM practices (using a conceptual framework of organizational ambidexterity to represent the dynamic environment (Birkinshaw \& Gibson, 2004; Gabriel \& Diefendorff, 2015; Junni et al, 2013, 2015)) offers insights into the prevalence of resilience and 'extremes' in organizational quotidian activity and moments. Organizational ambidexterity provides the framework and opportunity to generate a more granular understanding of resilience behaviors and sensemaking (Weick, 1995) among individuals in organizational settings. Moreover, the paper questions competing roles of 'positive' and 'skeptical' portrayals of resilience across organizational ambidextrous boundaries. Thus, the argument generates the following research question:

How do positive and skeptical individual portrayals of resilience within HRM practices operate across the exploitative and explorative ambidextrous organizational boundaries?

The paper is structured as follows: first, it considers the literature on resilience and relates this to prevailing understandings of notions of 'extremes'. The argument builds and explores an organizational ambidextrous theoretical framework within a qualitative research methodology using two illustrative contexts: a pan-international military organization and a quasi-governmental training organization. These furnish data which illustrate normative and alternative representations of extremes and the consequences for individual sensemaking and HRM practice. The argument develops and contextualizes alternative and deeper 
understandings of resilience and their role in sustaining (or detracting from) strategic HRM practices and performance. Finally, a range of implications and conclusions are presented.

\section{Casting the 'extreme' in resilience: micro and macro-perspectives}

Resilience is an increasingly prescient topic and can be prima facie understood as the development of capacities by individuals, groups and organizations to display fortitude and coping mechanisms so as to be able to deal with challenging circumstances (Luthans, 2002; Fredrickson et al., 2003; Fletcher \& Sarkar, 2013; Pal, Torstensson \& Mattila, 2014; Ellenbogen, Klein \& Wekerle, 2014; Manyena, 2014; Pal, Walklate \& Mythen, 2014; Bardoel et al., 2014; Masarik, 2015; Branicki, Steyer \& Sullivan-Taylor, 2016). Resilience, and the need to develop this capacity, is often portrayed against a backdrop of ever-increasing and intensifying rates of change and activity in the modern world (Wilson and Ferch, 2005; Shin, Taylor \& Seo, 2012; Duchek, 2014; King, Newman \& Luthans, 2015; Bustinza et al. 2016). Moreover, it has been invoked as a necessary responsive characteristic to various situations including, for example, personal, political, financial, terrorist, resource (for instance, energy) and environmental (for example, climate change) crises (Fiksel et al 2015; Carvalho and Areal, 2016).

Therefore, overall, it is important to note that the topic of 'resilience' has been typically associated with 'extreme' contexts - in other words resilience is evoked primarily in relation to intense, major or heightened situations (Seligman, 2011; Wang, Cooke \& Huang, 2014; Schultz \& van der Walt, 2015; Badran \& Youssef-Morgan, 2015; Cooke et al, 2016; King et al., 2016). In this guise, Coutu (2002:52) for example, directly connects resilience with: ‘enormous stress and change' and Youssef and Luthans (2007:792) indicate that resilience may be: 'more relevant in organizations which are in extreme conditions...'. Therefore, the normative representation of resilience is one with a propensity to view resilience as a phenomenon essentially connected to large scale, extreme or macro-events. In terms of framing resilience, this is significant. Macro-events are kindred with modernistic understandings of social phenomena which tend to describe and analyse organizational contexts predominantly through a methodological approach of positivism and its mechanisms of reductionism, causality and quantification linked to a predilection towards notions of 
effectiveness, efficiency and performance (Clegg, Kornberger and Pitsis; 2011; Stokes, 2011; Alvesson and Willmott, 2012). Macro- and positivistic approaches can provide valuable insights into the overall macro-processes and modeling of resilience, however, they tend to focus less attention on the more micro- and individual aspects of human experience and perception (Ollier-Malaterre, 2010). Consequently, rather than seeing resilience as operating primarily in relation to macro-contexts, there is scope to identify resilience operating in more everyday settings.

The predominant macro-approach and atmosphere towards resilience carries over into strategic HRM practices. There are repeated calls for the development of resilience in teams and organizational HRM practices as well as overall corporate performance (Menguc \& Auh, 2008; Bardoel, Pettit, De Cieri, \& McMillan, 2014; Wang, Cooke \& Huang, 2014; McCray, Palmer \& Chmiel, 2016). In terms of HRM practices, modernistic organizational representations ascribe a dominant role of control to managers, in preference to other types of employee and tend to marginalize, or at best address superficially, more human dimensions of organizations. Moreover, the HRM literature frequently focuses on military cases in order to exemplify extreme cases (Casey, 2011). For example, a well-cited case analyzes the rigors of SEAL military personnel training (Lengnick-Hall, Beck \& Lengnick-Hall, 2001). In addition, Seligman (2011), also examining resilience and extremes in military contexts, asserted that the resilience challenge is to support the middle-band performing personnel (soldiers) towards top-band performance. From such work, it is possible to imply that individuals who display resilience are unlikely to be resilient in an identical manner. Such diversity in employee reactions to extreme situations requires a flexible approach and has implications for the design and implementation of HRM practices. While the work of, for example, Lengnick-Hall, Beck \& Lengnick-Hall (2001) and Seligman (2011) focuses on contexts which would normatively be considered 'extreme', i.e. war and conflict, this nevertheless raises a corollary question concerning the validity and applicability of these conceptualizations of 'extremes' to wider non-conflict organizational and quotidian settings (Lee, Hong \& Avgar, 2015).

'Extreme’ contexts such as military cases may seem distant environments from, for example, a civilian or non-military environment (Bonanno, 2004; Roisman, 2005; Bonanno et al, 2015). However, as commentators have underlined, there is a wide range of parallels between supposedly different military and civilian situations (see for example, Stokes, 2007, and 
Stokes \& Gabriel, 2010) and that there may well be moments when, as Conway \& Monks (2011:199) indicate that 'ambivalence' or differing forms of 'sense-making' are instrumental (see also Yagil \& Medler-Liraz, 2013). Thus, rather than casting resilience uniquely as a response to crises, major events, 'extreme' incidents or specific sectorial contexts (i.e. military or emergency services), alternatively, it may be pertinent to consider the possibility of recognizing the 'extreme' as an integral micro-aspect of everyday occurrence intertwined and interconnected with more readily recognized wider macro-institutional effects (kindred with De Certeau, 1998; Lefebvre, 2002). The development of a complementary, everyday, micro-perspective aligns with a more critical perspective appreciation of resilience - one that that sees acts and moments of resilience as being rooted in the local, the individual, the multifaceted and the idiosyncratic. Through a critical lens, modernistic approaches, while offering insights into overall structures and framing, can nevertheless seem mechanistic, clinical and overly preoccupied with representing resilience in strongly delineated manners, focusing on 'hard' output-focused metrics such as profit, efficiency and effectiveness. These metrics may be favored over the contribution and influence of more humanized understandings of organizational contexts and their HR practices (Alvesson \& Willmott, 1992, 2012; Czarniawska, 1998; Dereli \& Stokes, 2007; Spicer, Alvesson \& Kärreman, 2009; Clegg, Kornberger \& Pitsis 2011, Willmott, 2013; Willmott \& Seabrook, 2014). As an illustration of a more quotidian extreme context Werner and Smith (2001) observe how disadvantaged children increased their resilience to adverse familial circumstances by engaging daily in problem solving and receipt of positive reinforcement. The authors highlighted the importance of a 'strong faith' and various forms of social capital (Kaufman \& Geroy, 2007). Similarly, Masten (2001), analyzing children growing up in challenging and disadvantaged circumstances, indicates importantly that there are many instances in which it is possible to talk about the 'ordinariness' of resilience (ibid.: 227). She notes:

'The great surprise of resilience research is the ordinariness of the phenomena... Resilience [...comes...] from everyday magic of ordinary, normative human resources in the minds, brains and bodies....' (Masten, 2001: 235)[Emphasis added].

Thus, the present argument also asserts that it is not only macro-form extreme events in relation to which it is important to identify the establishment of HRM practices, but also the quotidian micro-events and engagement with everyday life (Luthar, Cicchetti \& Becker, 2000; Stokes and Harris, 2012; Panter-Brick \& Leckman, 2013). In this way, resilience can 
also be viewed as underpinning organizational life and HRM issues dealing with: "ongoing daily hassles to major life events" (Fletcher \& Sarkar, 2013: 12) and therefore can be witnessed in myriad everyday contexts (Bonanno, 2004; Roisman, 2005; Bonanno et al 2015). In this vein, McLarnon and Rothstein (2013) provide valuable organizational examples of extremes in the micro-situation: an employee being fired; losing a major client contract; being unable to resolve an interpersonal conflict; or, having severe difficulty leading coworkers and subordinates. Fletcher \& Sarkar (2013:14) point out, following Davydov et al (2010), that it is likely that resilience mechanisms are diverse and "differ in relation to contextual severity, ranging from resilience against regular everyday hassles like work stress... to resilience against extensive stress such as bereavement”. In this regard it is also perhaps important to highlight the potential cross-cultural complexities which may play out in modern organizational contexts (Xing, 2016). However, equally, it is also important to note that resilience goes beyond 'mere' survival (Lengnick-Hall, Beck \& Lengnick-Hall 2011:243) and that there is a case for it to be accompanied by, for example, aspirational, spiritual and social values (Choi and Lee, 2014). The above tension between macro and micro-perspectives of resilience provide the means to develop a novel framework modernistic/critical-informed framework with which to inform the analysis of the literature and subsequent field data (following Cooper et al., 2017). This argument leads to the development of Proposition 1.

Proposition 1: Resilience within HRM practices occurs in micro-moments grounded in idiosyncratic and everyday manners (and this micro-foundational organizational ambidexterity view of resilience often challenges predominant macro-perspective of resilience).

The next phase of the paper further elaborates the conceptual framework of the argument inter-connecting notions of resilience and organizational ambidexterity (Limnios et al, 2014) with modernistic and critical approaches. This provides an important device for strategic HRM practice as it will allow managers to develop a richer understanding of resilience in the workplace. 


\section{Structuring the dynamics of resilience through organizational ambidexterity: the role of behavioral perspectives in relation to HRM practices}

The development of a modernistic-critical paradigm of resilience and extremes in organizations in relation to HR practices can be aligned in a valuable manner with the /concept of organizational ambidexterity (Duncan, 1976; Birkinshaw \& Gibson, 2004; Patel, Messersmith \& Leepak, 2013; Voss \& Voss, 2013; Smith, 2017; Stokes et al., 2015). Organizational ambidexterity postulates that organizations, and the people working with, and within them, are often confronted by an exploitative-explorative dynamic (Duncan, 1976; Tushmann \& O’Reilly, 1996; He \& Wong, 2004; Hill \& Birkinshaw, 2014; Jansen et al., 2008; O’Reilly et al., 2009; O’Reilly \& Tushman, 2011; Prieto \& Pérez Santana, 2012; Raisch \& Birkinshaw, 2008; Simsek, 2009; Hill \& Birkinshaw, 2014; Stokes, et al. 2015). Exploitative ambidextrous organizational behavior is characterized by a tendency to adopt postures which work with extant organizational resources within existing and known boundaries and constraints. Thus, exploitative stances tend to adhere more towards riskaversion and certainty seeking-type behaviors. As such, they can be seen to align readily with the normative positivistic and conceptualizations of organizations which propose clearly 'boundaried' and controllable domains. Moreover, within this perspective, 'extremes' are viewed as exceptional events for which HRM practices develop and implement procedures which, in turn, are anticipated as ensuring the well-being and performance of the organization. Typically, exploitative mindsets tend to view resilience in absolute and delineated terms as something that is employed to deal with periodic and exceptional, 'farend' spectrum events and situations (i.e. the typical and perhaps stereotypical 'extreme' representation of resilience). In essence, this may be viewed as a 'managerialised' approach to resilience - i.e. one in which resilience needs, and has, to be managed. While such exploitative stances offer apparent 'certainties' and clearly delineated boundaries, there also exists the potential downside of, for instance, not taking potential opportunities and encouraging innovation (Duncan, 1976; Birkinshaw \& Gibson, 2004; Stokes et al. 2017).

Alternatively, explorative ambidextrous positions point at mindsets which have a greater propensity to engage with innovation, creativity, discovery of new knowledge, resources and contexts (Benner \& Tushman, 2003; Bierly, Damanpour \& Santoro 2009). Therefore, in this regard, they are more aligned with risk-taking and a willingness to embrace uncertainty. Of 
course, such behavior may be accompanied by risks and uncertainties - i.e. outcomes cannot always be readily predicted or pre-determined and there could be important negative effects and consequences. This perspective reflects a more critical perspective of organizations. An explorative mindset sees extremes in a relativistic manner wherein such incidents are viewed as being equally prone to emerging in the myriad everyday and micro- nature of organizational life as much as in the more periodic and macro- perception of 'extreme' events.

The utilization of an organizational ambidexterity framework with which to explore resilience permits the establishment of an exploitative-normative position (aligned with modernistic assumptions) at the boundary of, and interacting with, an explorative-critical (aligned with critical assumptions) position. This encompasses a potent dynamic of perspectives in relation to resilience, extremes and behaviors with attendant consequences for HRM practices in organizations. A central point of this dynamic is the interface of the exploitative/explorative ambidexterity boundary which Raisch \& Birkinshaw (2008:401) identify as a space to examine more 'granular' (i.e. more micro as opposed to more macro) aspects. Commensurately, this means that in an organizational setting, on the one hand, it will be possible to evidence modernistic and managerialistic approaches to resilience - which cast it as primarily a 'positive' behavior to be used and managed by managers to prepare and deal with exceptional circumstances - and, on the other hand, there will be more criticallyinformed views which see resilience and extremes as prevalent and everyday occurrences that are played out in a wide range of micro-moments with a possible role for behaviors which question modernistic stances. Moreover in variegated globalized and internationalized $21^{\text {st }}$ century workplaces such approaches may also facilitate enhanced interaction and talent management between all parties (Liu, 2017, Liu and Almor, 2016; Stokes et al, 2016).

Notions of the 'positive' are important in understanding resilience and HRM practices within an organizational ambidextrous framework and the development of a more micro- and individual understanding. Within its dominant modernistic casting, resilience has frequently been associated in general terms with a 'positive' mindset or attitude i.e. resilience is generated or believed to be produced by a number of factors including 'positive psychological capacities' (Gupta and Singh, 2014). Drawing on the widely commented concept of Positive Organizational Behavior (POB) - an approach which reifies the 'positive' within understandings of resilience - Youssef \& Luthans (2007) suggest that: 'what is good 
about life is as genuine as what is bad and therefore deserves equal attention'. Equally, Peterson and Park (2006) underline the importance of adopting a positive approach in all circumstances embracing positive elements, such as for example, 'hope, optimism and resilience' (Youssef \& Luthans, 2007: 775). Thus, within modernistic accounts, skepticism and pessimism tends to be problematized and seen as eroding the capacity for resilience (Avey et al, 2012). Commensurately, modernistic perspectives are prone to emphasizing a relatively unproblematized 'positive' perception of the role of positive emotions and dispositions with which to underpin optimism, resilience and anticipated strategic HRM performance. For example, Seligman (1998, cited in Youssef \& Luthans, 2007:778) states:

'an attributional style that explains positive events in terms of personal, permanent and pervasive courses and negative events in terms of external, temporary and situation-specific ones. A pessimistic explanatory style does the opposite, thus undermining the favorable aspects of successes and exacerbating the destructive potential of failures.'

Yet, as Tugade and Frederickson (2004:320) note, it is difficult to determine, for instance, if optimism stems from resilience, or, resilience from optimism. They observed that even in high stress and demanding environments some individuals tend to exude positive thoughts and optimism. Importantly, in certain regards, they describe this as being linked to a 'Pollyanna effect' (ibid.: 331) in which individuals tend to focus overly, or in a forced manner, on perceived positive energies and forces around them (Grandey, Rupp \& Brice, 2015). However, a 'Pollyana' approach and positive disposition raises an important point since it alludes to the possibility of different forms of attitude and optimism operating across ambidextrous exploitative-normative and explorative-critical states (Lavie, Stettner \& Tushman, 2010). 'Pollyana-style' optimism linked to resilience can be seen as connecting with a more surface, synthetic (even, on occasion, naïve or insincere), form of optimism which is reactionary and effected as an automatic (perhaps rather unreflective) response - for instance, a standard construct of 'positive'-styled discourse commonly forms part of 'management speak'. Management speak employs phrases which in themselves appear effective and performative on a prima facie level but are often devoid of real meaning for a large number of individual employees (Watson, 2006). Due to their macro- and delineated nature, Pollyana-style optimism and management speak are more likely to be aligned with 
modernistic approaches. Nevertheless, managers who employ management speak may, for various reasons, believe wholeheartedly that they are communicating purposefully and meaningfully. Thus, inherently, a Pollyana-style optimism approach to building resilience is one that places control and responsibility on generating optimism under managerial control (sic: and potentially managerialist) and to some extent the formal HR department communications adhering to a unitary culture (i.e. single perspective on a corporate culture) rather than a pluralistic culture (i.e. accepting of multifarious perspectives on a given corporate culture) (Price \& Whiteley, 2014; O’Reilly et al, 2014). In other words, this perspective would essentially claim that it is a managerial responsibility to build morale and ensure progression towards managerially set organizational targets and goals (Harland, Harrison, Jones \& Reiter-Palmon, 2005). In this frame of reference, 'optimism', and 'being positive', become, a managerial device to be deployed to: “...help managers recognize employees at greater 'risk' of variable or eroded positivity" and this "will ensure that managers and organizations [have] more rigorous information regarding the positivity of staff” (Dawkins et al, 2013: 364). Such a managerialist outlook and environment may variously have negative effects and impacts on employees depending on their personality and interpretation (Stokes et al, 2016).

In contrast, perceptions of optimism and resilience within an explorative-normative approach involve charting challenging and potentially unpredictable terrain. In other words, without its predictive, boundaried modernistic basis to rely on, discourse founded on 'Pollyana' optimism and 'management speak' can appear impotent and meaningless for individuals. It is at these particular moments that, for example, alternative skepticism, optimism and humorinformed behaviors and responses may emerge. Lengnick-Hall, Beck \& Lengnick-Hall (2011) note that repetition or recurrence is a common feature of developing such everyday behaviors. Because critical forms of behavior are more prone to being sited individually rather than organizationally it is likely that explorative-critical approaches encompass more pluralistic forms. This idiosyncrasy may run counter to, and contradict, more managerially controlled normative, unitary (i.e. 'Pollyana'-style'.) approaches to developing optimism and resilience. Conway and Monks (2011) suggest that rather than viewing such postures as resistance they may be better considered as 'ambivalence' or differing forms of 'sensemaking' (2011:199). Thus, managers and employees, in these instances might chose to build corporate cultural understandings through mutual respect and recognition of differing stances. 
Consequently, where exploitative-normative and explorative-critical approaches operate in proximity and across organizational ambidexterity boundaries, tensions may ensue in complex manners (Mom, Fourné \& Jansen, 2015). Indeed, a key criticism of how 'positive' adaptation is conceived is that it over-emphasizes, and to some extent, (over)-simplifies individual and relational capacities (Fletcher \& Sarkar, 2013). Ungar (2011) and Ungar \& Liebenberg (2011), suggest that these myopias come from a predominantly Western discourse and therefore "lack[s] sensitivity to cultural factors that contextualize how resilience is defined by different populations and manifested in different practices. An explorative-critical framing linked to ambidexterity, offers the possibility of complementing understandings of positivity and developing a more socio-culturally rich perspective for strategic HRM practices. The foregoing discussion leads to the formulation of Proposition 2:

- Proposition 2: By understanding the operation of resilience across the exploitativenormative and explorative-critical organizational ambidexterity boundary a richer appreciation of resilience (and its composite elements of optimism and skepticism) is generated with which to inform HRM practices.

In summary, the predominant modernistic understanding of the literature on resilience characterizes 'positive' behavior in a particular kind of way. It suggests that being 'positive' is an inherent good and this can be underpinned by surface level (on occasion simplistic and naïve) managerially controlled optimism. However, explorative-critical perspectives offer complementary and alternative insights to prevailing views but remain under-examined. Organizational ambidexterity provides a conceptual framework with which to map and analyze the interface and interaction of differing normative and critical mechanisms of resilience (Hitt \& Ireland, 2002; Baker \& Miles-Watson, 2008). The preceding discussion has surfaced a number of competing paradigms and constructs and these are summarized in Table 1: 


\begin{tabular}{|c|c|}
\hline \multicolumn{2}{|c|}{$\begin{array}{l}\text { Table 1: The Interface of Resilience } \\
\text { Across Exploitative-Explorative Organizational Ambidexterity }\end{array}$} \\
\hline $\begin{array}{l}\text { Resilience in the } \\
\text { Exploitative-Normative Domain }\end{array}$ & $\begin{array}{l}\text { Resilience in the } \\
\text { Explorative-Critical Domain }\end{array}$ \\
\hline $\begin{array}{l}\text { Reflected by normative }- \text { modernistic } \\
\text { paradigms and characteristics } \\
\text { (Clegg, Kornberger and Pitsis; 2011). }\end{array}$ & $\begin{array}{l}\text { Reflected by critical perspective paradigms } \\
\text { and characteristics } \\
\text { (Alvesson and Willmott, 2012). }\end{array}$ \\
\hline $\begin{array}{l}\text { Often aligned with managerialistic behaviors } \\
\text { but structured approaches may be valuable. }\end{array}$ & $\begin{array}{l}\text { Supports individual and self-organizing } \\
\text { groups but may seem chaotic and } \\
\text { fragmented. }\end{array}$ \\
\hline $\begin{array}{l}\text { Resilience is commonly cast as a response to } \\
\text { an extreme event or circumstances } \\
\text { (Youssef \& Luthans, 2007). }\end{array}$ & $\begin{array}{l}\text { Resilience can be seen as an everyday act and } \\
\text { the idea of 'extremes' might be able to be } \\
\text { located in quotidian occurrences (Masten, } \\
\text { 2001). }\end{array}$ \\
\hline $\begin{array}{l}\text { Linked to resilience, performance and well- } \\
\text { being are generally perceived as a } \\
\text { managerially controlled construct. }\end{array}$ & $\begin{array}{l}\text { Performance and well-being are seen as } \\
\text { evolving as a result of idiosyncratic } \\
\text { responses and behaviors (Spicer, Alvesson \& } \\
\text { Kärreman, 2009). }\end{array}$ \\
\hline $\begin{array}{l}\text { Resilience mechanisms tend to produce } \\
\text { managerialistically informed and driven and } \\
\text { optimism (there is a risk that this could } \\
\text { become 'Pollyana' or management speak } \\
\text { type rhetoric and not be effective at } \\
\text { individual level. }\end{array}$ & $\begin{array}{l}\text { Resilience mechanism - individually and } \\
\text { group socially constructed giving rise to } \\
\text { skeptical, pessimistic, (dark) humor reactions } \\
\text { at individual level. There is a risk that } \\
\text { questioning may descend into cynicism. }\end{array}$ \\
\hline $\begin{array}{l}\text { Resilience typically characterised as } \\
\text { bouncing back and resurgence rather than } \\
\text { transformatory. }\end{array}$ & $\begin{array}{l}\text { Resilience typically cast as coping (linked to } \\
\text { concepts of agility, adaptability and } \\
\text { flexibility Chakravarthy, 1982; Shaw, 2012). }\end{array}$ \\
\hline $\begin{array}{l}\text { Views non-managerialistically compliant } \\
\text { resilience and optimism as unacceptable } \\
\text { resistance which needs to be mitigated or } \\
\text { removed (Seligmann, 1998). }\end{array}$ & $\begin{array}{l}\text { Views managerialistic approach to optimism } \\
\text { as naïve, surface-level and coercive. } \\
\text { Engagement in various forms of resistance } \\
\text { (humor, 'soldiering') } \\
\text { (Conway \& Monks, 2011). }\end{array}$ \\
\hline $\begin{array}{l}\text { Critical perspective derived resistance } \\
\text { viewed as most likely to inhibit or damage } \\
\text { performance. }\end{array}$ & $\begin{array}{l}\text { Normative-modernistic perspectives seen as } \\
\text { oppressive, myopic and restrictive in the } \\
\text { manner in which they approach and control } \\
\text { the workplace. }\end{array}$ \\
\hline
\end{tabular}


Figure 1: Conceptual framework of the study

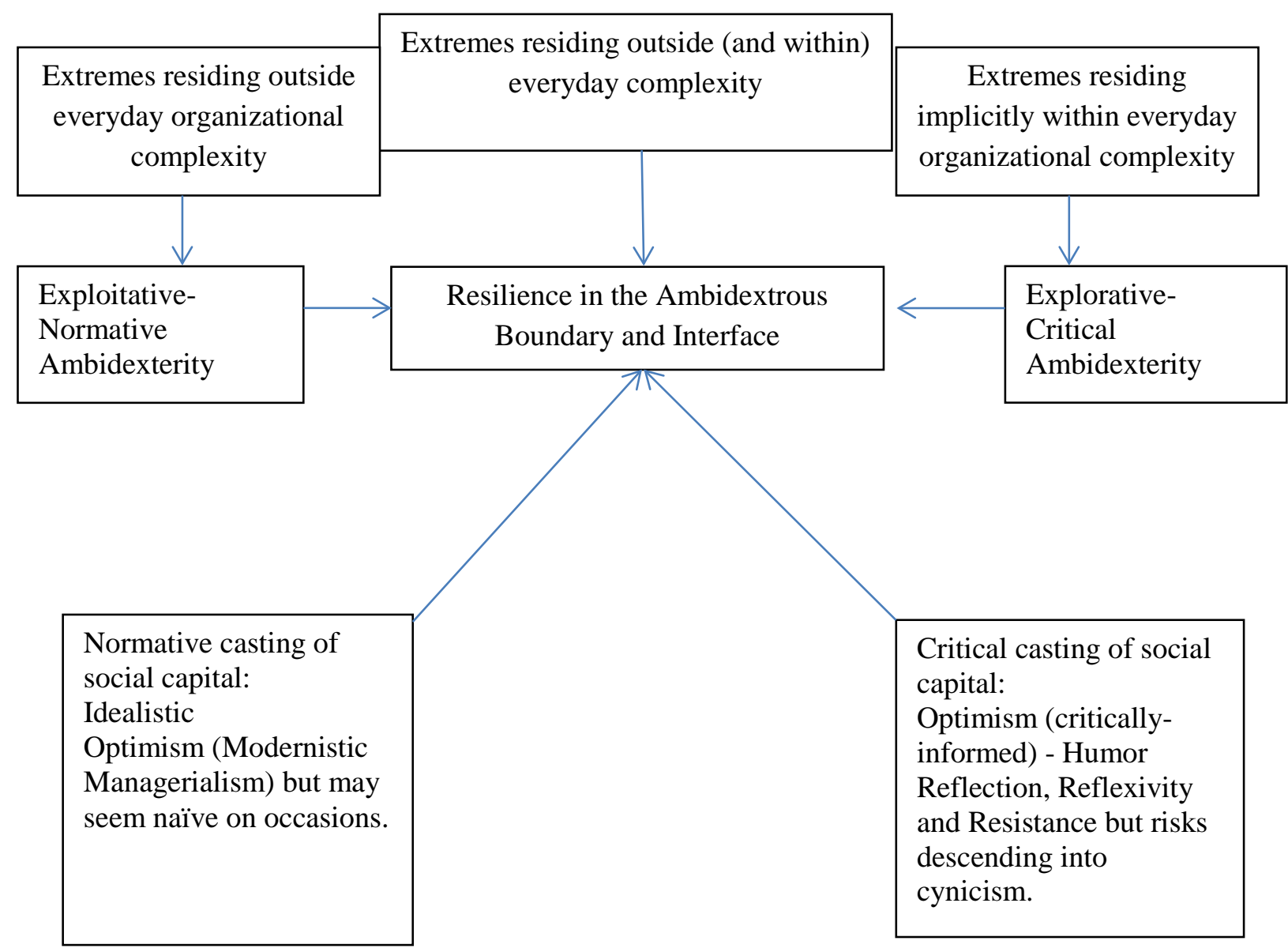




\section{Methodology}

The research adopts a qualitative approach (Creswell, 2009; Denzin \& Lincoln, 2011; Silverman, 2011). The study examines resilience in relation to strategic HRM practices in two prima facie differing contexts within a framework which allows the development of indepth fine-grained and granular data. This provides opportunities to understand and contextualize the operation of resilience at the ambidextrous exploitative-explorative boundary (Lubatkin et al, 2006; Edmondson \& McManus, 2007; Eisenhardt \& Graebner, 2007). Overall, the study was mindful of ensuring rigor in the qualitative study and while not expressly adopting, for example, a Gioian-style approach, it was nevertheless respectful to the issues of structure within methodology extolled therein (Gioia, Corley \& Hamilton, 2013). The first field context examines a quasi-governmental organization (QGO) in the training and development sector of the UK economy. The second field data site explores resilience in a military organization (MILORG) operating in Afghanistan. Following Siggelkow (2007) and his identification of the need to complement single instances with secondary supporting and triangulating observations, the function of the MILORG case in the study is to operate as a relative comparator to the QGO domain (and in particular to be able to explore the nature of 'extremes'). The research employed a combination of semi-structured interviews and participant observation (Spradley, 1980; DeWalt \& DeWalt, 2011; Gubrium et al., 2011). The MILORG study illustrates the operation of resilience in what would normatively be considered as an anticipated prima facie example of a normatively extreme and dynamic situation - i.e. a military conflict context. However, the data also allow the detailed examination of particular localized settings and the presence of, for example, banality and idiosyncratic humor in the everyday circumstances of extreme contexts (Thomas and Myers, 2015).

The selection and development of the two contexts are based on negotiated high-level contacts which provide insights to specific questions and situations thereby allowing endogenous factors to be developed (Graebner \& Eisenhardt, 2004; Siggelkow, 2007; Riad \& Vaara, 2011; Riad, Vaara \& Zhang 2012). In this way, the cases reveal the differing operation of resilience at the interface of exploitative and explorative organizational ambidextrous dimensions. The inductive methodology develops primary research data which permit the exploration of situational dynamics (Langley et al, 2013) and which can produce rich information and insights on behaviors. 
Template analysis was employed to examine the data (King \& Horrocks, 2010).This approach involves the identification of key emergent themes and sub-themes in relation to rich and complex data. The analytical process is conducted through reading repetition involving the research group members which reinforced reliability. The initial readings provided what are termed a priori codes and, using these codes as structure, the follow-up readings identified 'segments' which align within the a priori codes. In the instances when segments cannot be allocated, a consideration has to be made as to whether these should generate a priori codes. In terms of generalizability, the field studies focus on the contexts they exhibit however it is plausible that the findings from these instances will be recognizable and applicable to wider contexts. Importantly, their purpose is to offer rich, in-depth data located in specific contexts (Eisenhardt \& Graebner, 2007; Siggelkow, 2007). Moreover, within the two settings examined, Johns (2006) signals the role of context as an influencing factor on research results which have been noted. Johns identified several particular manifestations of context including context as: the salience of situational features; situational strength; cross-level effect; configuration or bundle of stimuli; event; and shaper of meaning. This study is cognizant of this range of features and although the one of case contexts is situated in a conflict zone, in accordance with Masten (2001) and observations regarding the ordinariness of resilience, we aim to identify how informal and ordinary settings of context are evidenced. Moreover, Tsang (2014) makes the important point that qualitative focal data (rather than large-set quantitative data) has the potential to offer better possibilities for generalizations in relation to the development of theoretical frameworks and that has been a purpose in the present study. 


\begin{tabular}{|l|l|c|}
\hline \multicolumn{1}{|c|}{ Organization } & \multicolumn{1}{|c|}{ Respondent } & Quantity \\
\hline Military (MILORG) & Base Commander & 1 \\
\hline & Communications Officer & 1 \\
\hline & Liaison Staff & 4 \\
\hline Quasi-Government (QGO) & Operational Staff & 6 \\
\hline & & 3 \\
\hline & Service Director & 11 \\
\hline & Product Manager & 2 \\
\hline & Trainer-employee & 3 \\
\hline
\end{tabular}

Table 2: Respondents in the Quasi-Governmental Organization and the Military Organization.

\section{Field data contexts}

The Quasi-Governmental Organization (QGO)

The Quasi-Governmental Organization (QGO) field data were developed between 2012 and 2014. The QGO was located in the United Kingdom and has both domestic and overseas operating centers and partnerships. Its primary activity was the design and delivery of training programs. The organization was divided up into a number of business units which deliver specialist subject areas focusing on particular subject areas. The organization employed approximately 400 staff and the research was undertaken in the corporate-facing section which comprised 70 staff. Much of the day-to-day activity in the QGO would be typically described as commercial and administrative procedural activity. The QGO organization had undergone a wide range of senior manager 'top-down' directed changes in recent years. This has led to a number of structural changes which may be seen as managerialistic in nature fitting with the general trends and ambiance in the business sector in which it is located.

\section{The Military Organization (MILORG)}

These field data were developed between 2008 and 2009 in a headquarters which formed part of the International Stabilization Force (ISFOR) in Afghanistan (2009). The organization 
needed to design and develop a resilient and robust organizational structure staffed with suitably qualified and experienced multi-national personnel. In consultation with all the troop contributing nations (TCNs), the HRM team (undertaking organizational HRM planning and sustainment) had to design, build and augment the organizational structure that would deliver organizationally resilient staff with multi-national and multi-cultural military and civilian personnel; their main deliverables were to plan, command and support the international peace-keeping force activities across the region. The multinational force had a significant Dutch contingent. The mission task was to gradually withdraw the Dutch team and replace it with an incoming British team. This had to be accomplished while not compromising the operation of the headquarters. The HR team had to liaise with the various parties to ensure the smooth transition. Replacements were staggered in order to facilitate a progressive transition. This involved continuity and succession planning. There was a constant risk of local political interference where a senior officer would try to over-staff an area of the headquarters in order to secure political influence. It is important to note that MILORG was chosen as a dataset to provide an opportunity to explore and question resilience and organizational ambidexterity in a prima facie 'extreme' environment in contrast to a more notional non-extreme setting (QGO) (following Stokes (2007)). This permitted the examination of extremes in 'everyday' settings in both contexts.

\section{Findings}

The findings are presented in parallel with key constructs emerging from the argument. A detailed summary with supporting interview evidence of the exploitative/explorative frame of reference are elaborated in Table 3 - Findings Summary. Importantly, it should be noted that frequently respondents did not explicitly refer to 'resilience' in their comments and reflections. Rather, the notions of resilience were contained in comments linked to coping, carrying on, and dealing with situations. Often a cynical or skeptical humor accompanied these remarks. 


\section{Exploitative-explorative frame of references (managers and employees operating across the organizational ambidexterity boundary)}

The findings, in relation with the literature discussion, identified a number of aspects in which an ambidextrous dynamic regarding resilience operated (Birkinshaw, and Gibson, 2004; Patel, Messersmith and Leepak, 2013). A dimension within the data illustrating the exploitative-normative casting of resilience and performance was the role of strong rhetoric driven by dominant managerialistic atmospheres. This was typified by exhortations and proclamations such as: 'Yes, we must make the organization the leading one in the country' [CEO-QGO] and 'We must do this [mission] for the honour of the regiment' [MILORG].The tenor of such statements similarly extolled employees to, at least prima facie, perform and publically display happiness and well-being and seemed to represent standard strategic HRM policy-type statements. In contrast the explorative-critical perspective was typified by more 'sceptical' narratives that challenged the prevailing orthodoxy. For instance, a MILORG young liaison officer (B) commented that: 'I know in the past we have to tackle this situation in a particular way, but maybe it's time for something new'. The implication being that resilience was being eroded by the repetitive nature of actions. This exploitative-normative approach to resilience offered itself as the way that tasks should be developed. It was common to see postures adopting more explorative-critical behaviors as forms of resistance and a detraction from managerial control and efforts. Moreover, in the two case contexts, exploitative-normative castings of resilience tended to portray resilience as a phenomenon required to address apparent extreme situations (Roisman, 2005; Bonanno et al, 2015). This was countered and contradicted by more explorative-critical understandings which offered data showing resilience residing in more individual or small group everyday-centred relations (Purcell, 1987; Purcell and Gray, 1986) and that the notion of what may count as 'extreme' was relative: "We have to do something different - the pressure is now - it is not waiting as a big thing ahead, it is daily - hey ho same old mess but we carry on" [Trainer-Employee D QGO].

Interestingly, the above was equally found in the situation of MILORG which, being a military organization, might have been more stereotypically anticipated to present 'classical' extreme situations. However, individuals seemed as preoccupied with daily crises as, for instance, major (macro-) events. Interestingly, while both organizations were experiencing differing forms of extreme (fighting a war (MILORG) as opposed to disruptive office 
organizational change (QGO)), both organizations reported similar responses to managerialist advocacy to 'be positive'. In both contexts, such advocacy often seems to have a denigrating effect on levels of resilience. In response to the research question and Proposition 1, operational and active resilience seemed much more rooted in individual sensemaking and responses. Most, but not necessarily all, of the managerial actions would normatively be situated in an exploitative domain. Yet, there was evidence of skepticism and resistance to the status quo but in the main this was a resistant response by individuals to managerialist statements.

\section{Structure and form}

The exploitative-normative casting of resilience and performance was evidenced by a focus upon targets and key performance indicators. The agency of these aspects was primarily managerial. In the QGO, this was evidenced by the CEO who explained that: 'We need to set KPIs and managers need to ensure that these are achieved. Each department head needs to monitor this.' The importance of metrics was also observed in the MILORG when the Base Commander commented that: 'We must deliver against the command plan.' These approaches were illustrative of a unitary (rather than a more pluralistic) approach to resilience (Lengnick-Hall, Beck \& Lengnick-Hall, 2001; Seligman, 2011). Nevertheless, the explorative-critical casting of structure and form differed from the exploitative-normative approach in that performance measures and objectives were established by collegial action of self-organizing groups who worked together to develop consensus and agreement rather than 'blindly' following managerial prerogatives and directives. This was illustrated by the comment of QGO trainer-employee (C) who said that 'It seems like a very functional and mechanistic way to run an organization. There doesn't seem to be any reflection or thinking going on. It is mindless management.' There was also evidence of occasions where employees resisted and 'quietly ignored' edicts on KPIs and worked to deliver 'acceptable' results in alternative ways. These resistance approaches pointed at a desire to establish structure and form through more iteratively derived 'bottom-up' forms of social capital and processes (following Ungar, 2011, Ungar \& Liebenberg, 2011) rather than by 'top-down' managerial directives. In summary, and informing the research question and Proposition 1, it is clear for many employees that management resilience was driven by edicts and metrics. For a number of non-managerial employees, resilience was more derived by self and smallgroup development (Purcell, 1986) in a quotidian manner and this tended to push back across 
the organizational ambidexterity boundary. This pointed at a challenge for HRM processes to try to move beyond these modes of organizational ambidexterity dynamics.

\section{Framing of resilience}

As discussed above, resilience can be cast variously in exploitative-normative and explorative-critical organizational ambidextrous contexts. In the former, resilience is regarded as a response to infrequent 'extreme' events or circumstances; while in the latter resilience is often seen as a routine everyday act that is a fundamental element of lived experience (following, for example, Newman et al, 2014; Fletcher \& Sarkar, 2013; Robertson et al., 2015). The exploitative-normative casting of rare and unusual events (sic: extremes) was evidenced in the QGO by trainer-employee (F) who commented that: 'Project $\mathrm{X}$ is a really big opportunity and very exciting. A real chance for all to shine.' Likewise, in the MILORG a Captain (Operational Staff Respondent C) serving in Afghanistan emphasised this point when he explained that "This is what your training has prepared you for, so remember your training'. The implication being that resilience will be, or take effect, as a result of the training. In contrast, the explorative-critical casting of resilience was illustrated by a QGO team member who explained that: 'Project X is the "same old, same old” we have been here before. It is nothing special'. Similarly, the everyday lived experience of resilience was reflective by a MILORG Non-Commissioned Officer (Respondent Operational Staff B) when she asserted that: 'We have been on active duty so often we know what we are doing know and it is only the new bosses who need educating.' In other words, these latter respondents indicated that resilience and familiarity were 'in-built' and the events and processes being presented by some parties as 'extreme' were not necessarily felt to be the case by others. The experience of resilience was often felt equally across the organizational levels and while many attempts to extol resilience emitted from senior managerial positions, this was not automatically a managerial/employee split (see for example data in 'Framing of Resilience Table 3).

Following Proposition 1, it was evident that many people, in both case organizations, were 'feeling' pressure and extreme moments in what could be termed their everyday activities and not simply at macro-type 'extreme' events (conflict, redundancies, etc.). Importantly, it should be noted that respondents did not commonly talk directly, or overtly, about notions 
such as 'resilience' or 'resistance'. Thus, regarding Proposition 2, the evidence of these is more implicit and portrayed by the language they use and this is an important observation for HRM processes as the issues may be covert and embedded rather than on immediately evident.

\section{Framing of performance and performativity}

The exploitative-normative casting of performance was akin to that of the casting of structure and form in that performance was seen as a construct normatively measured by metrics and owned by managers. In contrast, from an explorative-critical perspective the data seem to suggest performance as the product of a collaborative endeavour that built and developed values. The exploitative-normative stance was evidenced in the QGO by a Product Manager (C) who explained that: 'We do need to get more efficient. We just don't have adequate management information from the centre. If we had that, people can work more effectively and they will feel happier.' A HR Officer in the MILORG (Operational Staff E) also highlighted this perspective when he commented: 'With a reduction in staff we need to become more efficient and agile... We still need to meet the demands of the Command Plan' thus implying that resilience would come from adopting a more explorative disposition. The explorative-critical perspective on performance was seen in the observation made by a Trainer-Employee (K) working in the QGO when she commented: 'I'm not sure there is much thinking about useful and real outcomes going on'. In the MILORG a Senior Officer (Liaison Staff D) explained that: 'We have been given this new IT kit. In spite of HR's claims we haven't been given adequate training yet we are still expected to be as efficient and effective as before.' This resonates with the explorative-critical stance because it challenges the 'managerial' view advanced by the HR department that adequate IT training had been provided and implies skepticism of these claims. In essence managerial rhetoric and assertions seemed to be met with a degree of cynicism and suspicion. In relation to the research question, the themes of performance resonated across the organizational ambidexterity divide. Within exploitative contexts, it tended to be discussed more as a rhetorical exhortation or imperative (linked to edicts, metrics) whereas in explorative modes it tended to be seen in a more granular fashion (operating at the individual and small group dimensions). 


\section{Framing of well-being}

The comments of respondents reported well-being as being a significant aspect of resilience. The exploitative-normative casting of well-being positions it as a partner aspect of resilience orchestrated by managers and a presumed necessary condition for the maintenance of performance. In contrast, from the explorative-critical stance well-being was linked to a sense of 'everyday' health and happiness which is informally discussed and shared with friends, colleagues and co-members of teams and groups (aligned to De Certeau, 1998; Lefebvre, 2002; Werner \& Smith, 2001). The exploitative-normative casting of well-being was highlighted by the message sent by the QGO Administrator (A) regarding yoga classes: 'Access to yoga classes will be available [through the central services] to help remove stress and tension. Please sign up as soon as possible as places are limited'. In this way resilience and well-being were envisaged as being reinforced. Similarly, managerial orchestration of well-being initiatives was further evidenced by the Service Director working in the organisation. He commented: 'Fruit for [company provided working] lunches is so much healthier than sandwiches'. This fundamental change was made without consultation or discussion with staff and as a measure to reinforce resilience (i.e. through healthy eating) was perceived as high-handed. Evidence for exploitative-normative castings of well-being in the MILORG was provided by the brief comment of the Base Commander who relayed the message that: "The Padre is always available if you need". As a form of resilience HRM practice this seemed to be largely treated with derision by staff. The explorative-critical stance of well-being is captured in the aside comment of a QGO employee who said that: 'I think my health and what I do with and to my body is largely my own business and not for anyone to dictate to me about - if I want to get fat that is my business - up yours!' [Traineremployee L]. Here, the resilience seemed to be more of a force aligned against and resisting managerialist impositions than dealing with the challenges of the business, Similarly, MILORG clerk indicated his frustration with the prevailing orthodoxy when we asked "Why am I forced to do an annual fitness test when I have an administrative job?.' [Operational Staff G].

Thus, linked to the research question, in the above measures it can be seen how resilience operates in tandem with notions such as well-being. In exploitative modes, well-being is seen attempting to reinforce resilience in a managerialist manner. Alternatively, sensemaking with 
regard to well-being and resilience also operated at more individual employee and small group levels. In other words, in line with Proposition 2, it is valuable for HRM processes to appreciate that individuals see well-being as important for resilience but do not like to be told how to pursue well-being by exploitative managerialist edicts purporting to be innovative and explorative.

The exploitative-normative casting of well-being was often linked to the presumed need to adopt a positive attitude and was illustrated effectively by the comment in the QGO Senior Management written statement that emphasized that: 'We all need to be positive about this' and by a QGO Product Manager (B) when he said: 'We are going to be, and indeed we are, a world class organization!'. Some employees were convinced by this exhortation yet for those employees of more explorative-critical stances this was seen as more akin to 'Pollyana-style' thinking (after Tugade and Frederickson, 2004:320). A QCO employee commented: 'This fluffy silliness - 'let's all be positive' - stuff is doing my head in’ It is just nonsense' and 'If I hear one more speech about being positive and upbeat I will scream. It just seems to be a silly game that the in-crowd are playing with the managers'. The respondent then comically mimicked a member of the 'in-crowd'. Similar skepticism was expressed by a NonCommissioned Officer in the MILORG when he commented 'I guess we will be playing 'buzz-word bingo' again when 'the boss' [sic: the commander] briefs us.' [Liaison Staff D]. The humor and skepticism seemed to play a role in helping these individuals to develop forms of resilience within localised and small group settings which connects with, and supports, Proposition 1.

\section{Discussion and conclusions}

\section{Resilience through the lens of organizational ambidexterity}

This study has sought to contribute to the conceptual imbalance that prevails within extant resilience literature. In particular, the lens of organizational ambidexterity permits the development of a theoretical base with which to reconceptualize and extend resilience beyond 'extreme' understandings (Sarker, 2013; Wang, Coke \& Huang, 2014; Schultz \& van der Walt, 2015). The methodological approach and framework permitted an examination of resilience linked to extreme situations (as outlined by Youssef \& Luthans, 2007) within 
contrasting contexts. Indeed, the data indicated the challenges of building resilience (and kindred aspects such as well-being and performance) through managerialist exhortations and pronouncements. For instance, advocacy to 'be positive' often seem to create innovative and explorative forms of resistance which served to discount the impact of such statements. The perceived 'traditional' 'extreme' context of the military organization enabled insightful comparison and contrast with the civilian organization but showed that everyday interactions were at the center of HR practices and exchanges in both organizations (Cornum, Matthews \& Seligman, 2011; Seligman, 2011). The findings within both organizations highlighted similar perceptions and complexities when managing staff, especially regarding residual impacts post-organizational changes. However, what was apparent was the way in which extremes could be felt at an everyday level and in relatively small but important ways. In other words, how employees dealt with 'extreme' situations left an imprint on their perceptions of the organization that lingered far beyond the time period when the events occurred. Indeed, this does have an impact on workplace atmospheres and does need to be carefully managed to ensure the well-being and performance of affected individuals and those around them (De Certeau, 1998; Lefebvre, 2002; Werner \& Smith, 2001). The everyday micro-moments (Masten, 2001; Stokes \& Harris, 2012) drawn from the comparisons of exploitative-normative and explorative-critical perspectives set resilience as operating across a spectrum, whereby it is clear from the data that employees are continuously demonstrating various forms of resilience - moving from positive to pessimistic postures (Bonanno, 2004; Fletcher \& Sarkar, 2013; Roisman, 2005; Bonanno et al, 2015). In other words, resilience needs to be seen as a human experience that is present, and takes place, in individuallycentred, micro-moments, albeit collaborative, rather than just viewed as being as primarily and uniquely located in organizational contextual macro-settings. This has important implications for manager:employee relationships and the kindred and emergent talent management issues (Liu et al, 2017).

Thus, from a conceptual point of view, differing perspectives on resilience are effectively presented using an exploitative-explorative dynamic. The normative versus critical interaction within organizational ambidexterity (Alvesson \& Willmott, 2012; Raisch \& Birkenshaw, 2008) of the findings identifies the importance for strategic HRM of not merely managerializing or marginalizing approaches to resilience (exploitative), but also embracing more nurturing approaches that recognize resilience as a constructed, nurtured and embedded part of everyday working life (explorative). Alternatively expressed, employees have to 
engage with, and survive, the banality of the quotidian 'trials and tribulations' of organizational life (Seery, Holman \& Silver, 2010). This builds a response to the research question regarding how resilience is present, and operates, through the ambidextrous boundary of exploitative-normative and explorative-critical approaches. In this way, Proposition 1 is supported as the critically informed micro-outlook challenges the reductionistic macro-accounts, i.e. the critical micro-accounts offer deeper insights and meaning regarding the everyday impact of constructing resilience in the face of HRM practices and actions. However, the research also underlines that both exploitative-normative and explorative-critical postures (i.e. not exclusively) towards resilience are likely to be operating in any given organizational context. To further amplify this point, it can also be seen that resilience is not uniquely or primarily linked to macro/extreme explorative castings of events and situations. The argument demonstrates how perceptions of 'extreme', and the resilience required to deal with these situations, equally reside in apparent everyday exploitative contexts. The development and affirmation of Proposition 1 exemplifies and attests to this observation.

\section{Structure and form and the faming of resilience}

Exploitative-normative approaches to casting resilience have tended to construct unitary and more mono-dimensional representations of culture through which rhetoric of well-being and performance can be extolled. The findings and discussion have provide insights into the role of, particularly explorative-critical approaches in developing more pluralistic groupings of sensemaking (Weick, 1995). Indeed, more skeptical forms of resilience are perhaps more likely to fragment a unified culture - some may argue this, in some regards, is indeed its very purpose - as self-organizing and self-identifying groups emerge. Proposition 2 addresses this tension and the study demonstrates that there is scope to perceive and understand resilience in a range of ways. A more processual appreciation of resilience, linked to phenomena such as explorative-critical, in association with exploitative-normative, understandings of resilience, acknowledges that more sceptical forms of resilience exist i.e. resilience and the humor and behavior that evidences it can be seen as residing not only in extremes contexts but also in more everyday settings (De Certeau, 1998; Lefebvre, 2002; Stokes \& Harris, 2012). Thus while explorative-critical forms provide a potential balancing mechanism on the more 'Pollyana' forms of approach to resilience (and their promises for performance) equally, 
exploitative-normative postures offer some structures and checks on cultural collapses towards in-grained cynicism (De Dreu, 2008; Im \& Rai. 2008). A surfacing and appreciation of differing incidents and manifestations of resilience facilitates a potentially richer understanding of how varying perspectives can reside simultaneously within organizational ambidextrous arenas.

The findings and discussion demonstrate the possibilities for moving beyond uniquely positivistically-styled outcomes of resilience (Marescaux, Winne \& Sels, 2013; Newman et al, 2014; $\mathrm{Hu}$ et al, 2015). Interconnecting these elements through organizational ambidexterity (Fletcher \& Sarkar, 2013, Robertson et al, 2015, Leipold \& Greve, 2009) underline that it is possible to see how exploitative-normative accounts risk employing relatively simplistic managerial rhetoric to convince and invoke employees into actions. Within the POB-type approaches discussed above, this was couched as a Pollyana-type effect whereby: 'if we say everything is alright then it is, and will be, alright' which is clearly problematic in dealing with the realities of situations be they extremes as understood in a normative context or 'extremes' within a more micro-setting and instance. In contrast, it is apparent that behaviors operating under explorative-critical modes of ambidexterity, for example, cynicism, skepticism, humor persisted as a 'fact of life' within both case organizations. From a managerialistic perspective, the presence and interface of this explorative dimension seemed to operate, for some respondents, as an 'inconvenient truth' for exploitative-normative context wherein such postures and discourses are viewed as resistance and destructive. Perhaps, a more constructive way forward for both well-being and performance might be a more converged perspective which sees the confluence of these differing forms of perspective as entirely quotidian and to be expected at the ambidextrous boundaries of organizational life. Overall, it could be proposed that the evidence suggests that perhaps an over-intensification of either particular 'Pollyana' or more resistant 'cynical' cultures are potentially unproductive for organizational and employee well-being and performance. Thus, managers and employees alike need to be mindful of not myopically pushing situations, be they in exploitative or explorative, into extreme modes. Thus resilience should be accepted as emerging from all behaviors (rather than uniquely a predominant Pollyana perspective) across the exploitative-explorative organizational ambidexterity spectrum. The overall interface and representation of the ambidextrous dialectic is assembled in Table 3: 
INSERT TABLE 3 - ‘A Conceptual Framework for the Interaction....' approximately here.

In summary, the paper has examined the extant literature relating to resilience and identified a predominant characterisation therein. Through the development of an organizational ambidextrous normative-critical framework the argument has reconceptualized resilience. This has afforded a variety of granular insights into the (extremes/everyday) perception and operation of resilience (including pessimism, naivety cynicism etc) at the interface of exploitative and explorative modes of organizational dynamics and provided a detailed response to the set research question. The argument underlines that managers, and indeed employees generally, can derive considerable benefit from acknowledging and working with a combination of Pollyana/sceptical approaches to resilience. In relation to developing these stances per se it is also important for these parties to seek to identify, and apply them, across varying exploitative/explorative organizational situations and move away from the current predominant casting of viewing resilience as being linked mainly to macro/extreme event/explorative contexts - i.e. resilience also happens in the micro/quotidian/exploitative setting and sceptical resistance to HRM initiatives has a potentially valuable role to play. In other words, the confluence of individual and organizational factors is significant and require consideration (Liu and Huang, 2018). The data and reconceptualizations have thus developed fresh insights and indications for strategic HRM policy and practices.

\section{Contributions and managerial implications}

The paper generates important insights in relation to how resilience operates within, and at the interface of, the states of exploitative and explorative OA. This is significant for HRM managers who, in contemporaneous contexts of swift flux and change, need to operate within such settings. In particular, the paper contributes novel understandings and framings of resilience. Moreover, by recognizing differing behaviors and understandings of resilience, the argument contributes awareness for managers of the importance of understanding different modes and traits of these phenomena (for example, forms of optimism and pessimism) and the need to work carefully and mindfully with them - crucially dislocating resilience from being cast uniquely through 'extreme' events and operating in the everyday but, at the same time, with a prevailing benefit of the structuring offered by modernistic 
mindsets. Explorative-critically informed forms of behavior, resistance and skepticism are an inevitable facet of organizations and it is unrealistic (on the part of HRM managerialists) to believe that only modernistically-shaped forms of behavior are the ones which merit existence. A staunch exploitative-normative mode of addressing such forms of behavior is to view them as undermining, threatening and problematic. For managers and HRM practitioners developing strategies, an alternative posture might be to view the varying (and to some extent competing) manifestations as 'information' and 'clues and cues' which are a holistic and important part of appreciating and working with an organizational culture and negotiating exploitative/explorative transitions and movement across the organizational ambidextrous boundary. Consequently, there is scope to recommend that HRM practices consider resilience beyond extremes and the development of such a posture will render management action more subtle and sensitised to differing exploitative and explorative postures towards resilience. This could be adopted by building alternative castings and appreciations of resilience into training and development programmes to assist coping with the paradoxical nature of ambidextrous organizational constructions.

\section{Implications for future research}

While exploitative-normative modes of management remain prevalent, and even dominant, in contemporary workplaces, this study explores the limitations of such approaches and their inability to produce more holistic high performance work-teams and human resource practices. There is scope to profile critically-informed constructions and perspectives in workplace settings. This would allow the hegemony of exploitative-normative managerialist approaches to be variegated and to be more responsive to the changes at the ambidextrous boundary.

\section{Conclusion}

The paper applies the concept of organizational ambidexterity to resilience in order to characterize different perceptions and constructions of resilience and, in particular, to introduce and illustrate differing understandings of 'extremes' in everyday contexts. Resilience is not a product formed uniquely in extreme contexts - it can also arise in an incremental and compound manner through the everyday occurrence of micro-moment. Individuals commonly display this in a range of implied, skeptical, humor-based ways, rather than explicit, manners and language. That is to say, it is unlikely to hear people use the word 
'resilience', but many comments made often revolving around skepticism and humor or simply carrying on point at resilient behaviors. The paper explores the operation of a range of perceptions and behaviors through a framework developed by the convergence of OA, modernistic and critical influences. This facilitates a deeper probing into phenomena of, for example, optimism, cynicism and humor which are frequently mentioned in the resilience literature but not particularly elaborated. HRM practices can benefit greatly from developing enhanced awareness of alternative and nuanced understandings of resilience by balancing attention paid to more managerialist and exploitative approaches at the expense of more critically couched stances and taken account of the latter in policy and strategy formation.

\section{References}

Alvesson, M. and Willmott, H. (1992) Critical Management Studies. London, England: Sage.

Alvesson, M and Willmott, H. (2012) Making Sense of Management: A Critical Introduction. London, England: Sage.

Avey, J. B., Reichard, R. J., Luthans, F. and Mhatre, K. H. (2011). Meta-analysis of the impact of positive psychological capital on employee attitudes, behaviors, and performance, Human Resource Development Quarterly, 22(2), 127-152.

Badran, M. A. and Youssef-Morgan, C. M. (2015). Psychological capital and job satisfaction in Egypt, Journal of Managerial Psychology, 30(3), 354-370.

Baker, C. and Miles-Watson, J. (2008). Exploring Secular Spiritual Capital; An Engagement in Religious and Secular Dialogue for a Common Future, International Journal of Public Theology, 2(4): 442-464.

Bardoel, E. A., Pettit, T. M., De Cieri, H., \& McMillan, L. (2014). Employee resilience: an emerging challenge for HRM. Asia Pacific Journal of Human Resources, 52(3), 279-297.

Benner, M. J., \& Tushman, M. L. (2003). Exploitation, exploration, and process management: The productivity dilemma revisited. Academy of management review, 28(2), 238-256.

Bierly, P. E., Damanpour, F., and Santoro, M. D. (2009). The application of external knowledge: organizational conditions for exploration and exploitation. Journal of Management Studies, 46(3), 481-509.

Birkinshaw, J. and Gibson, C. (2004), "Building ambidexterity into an organization”, MIT Sloan Management Review, Vol. 45, Summer, pp. 47-55.

Biron, M., \& Bamberger, P. A. (2011). More than lip service: Linking the intensity of empowerment initiatives to individual well-being and performance. The International Journal of Human Resource Management, 22(2), 258-278.

Bonanno, G. A. (2004). Loss, trauma, and human resilience: have we underestimated the human capacity to thrive after extremely aversive events?. American psychologist, 59(1), 20. 
Bonanno, G. A. (2005). Clarifying and extending the construct of adult resilience, American Psychologist, 60(3), 265-267.

Bonanno, G. A., Romero, S. A., \& Klein, S. I. (2015). The temporal elements of psychological resilience: An integrative framework for the study of individuals, families, and communities, Psychological Inquiry, 26(2), 139-169.

Branicki, L., Steyer, V., \& Sullivan-Taylor, B. (2016). Why resilience managers aren't resilient, and what human resource management can do about it. The International Journal of Human Resource Management, 1-26.

Bustinza, O. F., Vendrell-Herrero, F., Perez-Arostegui, M., \& Parry, G. (2016). Technological capabilities, resilience capabilities and organizational effectiveness. The International Journal of Human Resource Management, 1-23.

Carvalho, A \& Areal, N (2016) Great places to Work $($ : Resilience in times of crisis, Human Resource Management, 55(3), 479-498.

Casey Jr, G. W. (2011). Comprehensive soldier fitness: a vision for psychological resilience in the US Army. American Psychologist, 66(1), 1.

Chakravarthy, B. (1982) Adaptation: A promising metaphor for strategic management. Academy of Management Review. 7(1): 35-44.

Choi, Y., and Lee, D. (2014). Psychological capital, big five traits, and employee outcomes. Journal of Managerial Psychology, 29(2), 122-140.

Clegg, S., Kornberger, M., and Pitsis, T. (2011). Managing and Organizations: An Introduction to Theory and Practice. London, England: Sage.

Conway, E. and Monks, K. (2011). change from below: the role of middle managers in mediating paradoxical change. Human Resource Management Journal. 21(2): 190-203.

Cooke, F. L., Cooper, B., Bartram, T., Wang, J., \& Mei, H. (2016). Mapping the relationships between high-performance work systems, employee resilience and engagement: a study of the banking industry in China. The International Journal of Human Resource Management, 1-22.

Cooper, C., Stokes, P., Liu, Y. \& Tarba, S.Y. (2017). Sustainability management and organizational behavior: A micro-foundational perspective. Journal of Organizational Behavior, 38(9):1297-1301.

Cornum, R., Matthews, M. D., \& Seligman, M. E. (2011). Comprehensive soldier fitness: building resilience in a challenging institutional context. American Psychologist, 66(1), 4.

Coutu, D. (2002). How resilience works. Harvard Business Review, 80 (4), 46-55.

Creswell, J. (2009) Qualitative Design: Qualitative, Quantitative and Mixed Methods Approaches. London, Sage Publications.

Cunningham, I. (2010). Drawing from a bottomless well? Exploring the resilience of value-based psychological contracts in voluntary organizations. The International Journal of Human Resource Management, 21(5), 699-719.

Czarniawska, B. (1998). A narrative approach to organization studies. London, England: Sage. 
De Certeau, M. (1998). The Practice of Everyday Life: Living and cooking. Volume 2 (Vol. 2). Minnesota, U of Minnesota Press.

Davydov, D. M., Stewart, R., Ritchie, K., \& Chaudieu, I. (2010). Resilience and mental health, Clinical Psychology Review, 30(5), 479-495.

Dawkins, S., Martin, A., Scott, J., and Sanderson, K. (2013). Building on the positives: A psychometric review and critical analysis of the construct of psychological capital, Journal of Occupational and Organizational Psychology, 86(3), 348-370.

De Dreu, C. K. W. (2008). The virtue and vice of workplace conflict: Food for (pessimistic) thought, Journal of Organizational Behavior, 29(1), 5-18.

Denzin, N. and Lincoln, Y. (2011) The Sage Handbook of Qualitative Research. London, Sage Publications.

Dereli, C., and Stokes, P. (2007). Reconceptualising modernity for management studies: Exploring the tension between the scientific and the spiritual in the age of modernism. Philosophy of Management, 6(2), 131-139.

DeWalt, K and DeWalt, B. (2011) Participant Observation: A Guide for Fieldworkers, Lanham, Altamira Press.

Duncan, R. (1976) The ambidextrous organization: Designing dual structures for innovation. In Killman, R., Pondy, L. and Sleven, D. (1976). the Management of Organization, Volume 1:176-188, New York: New Holland.

Duchek, S. (2014). Growth in the face of crisis: the role of organizational resilience capabilities. In Academy of Management Proceedings (1, p. 13487). Academy of Management.

Edgar, F., Geare, A., Halhjem, M., Reese, K., \& Thoresen, C. (2015). Well-being and performance: Measurement issues for HRM research. The International Journal of Human Resource Management, 26(15), 1983-12.

Edmondson, A. C., and S. E. McManus (2007), Methodological Fit in Management Field Research. Academy of Management Review 32, no. 4.

Eisenhardt, K. M. \& Graebner, M. E. (2007), Theory building from case studies: Opportunities and challenges, Academy of Management Journal, 50(1), 25, pp. 32

Ellenbogen, S., Klein, B., \& Wekerle, C. (2014). Early childhood education as a resilience intervention for maltreated children. Early child development and care, 184(9-10), 1364-1377.

Fiksel, J., Polyviou, M., Croxton, K.L. \& Pettit, T.J. (2015). From risk to resilience: Learning to deal with disruptions, MIT Sloan Management Review, 56(2), 79

Fletcher, D. and Sarkar, M. (2013). Psychological resilience: A review and critique of definitions, concepts, and theory. European Psychologist, 18(1), 12-23.

Fredrickson, B. L., Tugade, M. M., Waugh, C. E., \& Larkin, G. R. (2003). What good are positive emotions in crisis? A prospective study of resilience and emotions following the terrorist attacks on the United States on September 11th, 2001. Journal of personality and social psychology, 84(2), 365. 
Gabriel, A., \& Diefendorff, J. (2015). Emotional labor dynamics: A momentary approach. Academy of Management Journal, 58(6), 1804.

Gibson, C and Birkinshaw, J. (2004) The antecedents, consequences, and mediating role of OA. Academy of Management Journal. 47:209-226.

Gioia, D. A., Corley, K. G., \& Hamilton, A. L. (2013). Seeking qualitative rigor in inductive research: Notes on the Gioia methodology. Organizational Research Methods, 16(1), 15-31.

Gittell, J. H., Seidner, R., \& Wimbush, J. (2010). A relational model of how high-performance work systems work. Organization Science, 21(2), 490-506. doi:10.1287/orsc.1090.0446.

Grandey, A. A., Rupp, D., \& Brice, W. N. (2015). Emotional labor threatens decent work: A proposal to eradicate emotional display rules. Journal of Organizational Behavior, 36(6), 770-785.

Gupta, V. and Singh, S. (2014) Psychological capital as a mediator of the relationship between leadership and creative performance behaviors: empirical evidence from the Indian R\&D sector. The International Journal of Human Resource Management, 25(10): 1373-1394.

Gubrium, J., \& Holstein, J. (2012), Narrative practice and the transformation of interview subjectivity. In Jaber F. Gubrium, James A. Holstein, Amir B. Marvasti, \& Karyn D. McKinney (Eds.), The SAGE handbook of interview research: The complexity of the craft. (2nd ed., pp. 27-45). Thousand Oaks, CA: SAGE Publications, Inc. doi: http://dx.doi.org/10.4135/9781452218403.n3

Harland, L., Harrison, W., Jones, J. R., \& Reiter-Palmon, R. (2005). Leadership behaviors and subordinate resilience. Journal of Leadership \& Organizational Studies, 11(2), 2-14.

He, Z. L., \& Wong, P. K. (2004). Exploration vs. exploitation: An empirical test of the ambidexterity hypothesis. Organization Science, 15(4), 481-494.

Hill, S. A., \& Birkinshaw, J. (2014). Ambidexterity and survival in corporate venture units. Journal of Management, 40(7), 1899-1931.

Hitt, M.A., \& Ireland, R.D. (2002), The essence of strategic leadership: Managing human and social capital, Journal of Leadership \& Organizational Studies, 9(1), 3-14.

Hitt, M. A., Keats, B. W., and DeMarie, S. M. (1998). Navigating in the new competitive landscape: Building strategic flexibility and competitive advantage in the 21st century. The Academy of Management Executive, 12(4), 22-42.

Hu, T., Zhang, D. and Wang, J. (2015). A meta-analysis of the trait resilience and mental health, Personality and Individual Differences, 76, 18-27.

Huang, Q., Xing, Y., \& Gamble, J. (2016). Job demands-resources: a gender perspective on employee well-being and resilience in retail stores in China.The International Journal of Human Resource Management, 1-19.

Im, G. and Rai, A. (2008). Knowledge sharing ambidexterity in long-term interorganizational relationships. Management Science, 54(7), 1281-1296.

Jansen, J. J., George, G., Van den Bosch, F. A., and Volberda, H. W. (2008). Senior team attributes and OA: The moderating role of transformational leadership. Journal of Management Studies, 45(5), 982-1007. 
Johns, G. (2006), The essential impact of context on organizational behavior, Academy of Management Review, 31(2): 385-408.

Junni, P., Sarala, R.M., Taras, V., and Tarba, S.Y. (2013). Organizational ambidexterity and performance: A meta-analysis. Academy of Management Perspectives, 27 (4), 299-312.

Junni, P., Sarala, R. M., Tarba, S. Y., Liu, Y., \& Cooper, C. L. (2015). The Role of Human Resources and Organizational Factors in Ambidexterity. Human Resource Management, 54(S1): s1-s28.

Kaufman. B. E. (2012). Strategic human resource management research in the United States: A failing grade after 30 years?. The Academy of Management Perspectives, 26(2), 12-36.

King. D. D.. Newman. A., \& Luthans, F. (2015). Not if, but when we need resilience in the workplace. Journal of Organizational Behavior, 37(5), 782-786.

Kaufman, N., \& Geroy, G. (2007), An Energy Model for Viewing Embodied Human Capital Theory, Performance Improvement Quarterly, 20 (1), 37-48.

Kossek, E. E., \& Perrigino, M. B. (2016). Resilience: A review using a grounded integrated occupational approach. The Academy of Management Annals, 10(1), 729-797.

Kostopoulos, K. C., and Bozionelos, N. (2011). Team exploratory and exploitative learning: Psychological safety, task conflict, and team performance. Group \& Organization Management, 36(3), 385-415.

Lavie, D., Stettner, U., \& Tushman, M. L. (2010). Exploration and exploitation within and across organizations. The Academy of Management Annals, 4(1), 109-155.

Langley, A., Smallman, C., Tsoukas, Haridimos and Van de Ven, A. H. (2013), Process studies of change in organization and management: unveiling temporality, activity, and flow. Academy of Management Journal, 6 (1), pp. 1-13, ISSN 0001-4273.

Lee, E. K., Hong, W., \& Avgar, A. C. (2015). Containing conflict: A relational approach to the study of high-involvement work practices in the health-care setting. The International Journal of Human Resource Management, 26(1), 100-122.

Lefebvre, H. (2002). Critique of Everyday Life (Vol. 2). New York, Verso.

Leipold, B. and Greve, W. (2009). Resilience: A conceptual bridge between coping and development. European Psychologist, 14(1), 40-50.

Lengnick-Hall, C., Beck, T and Lengnick-Hall (2011) Developing a capacity for organizational resilience through strategic human resource management. Human Resource Management Review. 21: 243-255.

Lepak, D. P., \& Shaw, J. D. (2008). Strategic HRM in North America: looking to the future. The International Journal of Human Resource Management,19(8), 1486-1499.

Liu, Y. (2017). Born global firms' growth and collaborative entry mode: the role of transnational entrepreneurs. International Marketing Review, 34(1), 46-67.

Liu, Y. \& Almor, T. (2016). How culture influences the way entrepreneurs deal with uncertainty in inter-organizational relationships: Returnee vs. local entrepreneurs in China. International Business Review, 25(1): 4-14.

Liu, Y., Sarala, R.M., Cooper, C. \& Xing, Y. (2017). Human side of collaborative partnerships: A micro-foundational perspective. Group \& Organization Management, 42(2):151-162. 
Liu, Y. \& Huang, Q. (2018). University capability as a micro-foundation for the Triple Helix model: the case of China. Technovation. https://doi.org/10.1016/j.technovation.2018.02.013

Lubatkin, M. H., Simsek, Z., Ling, Y. and Veiga, J. F. (2006). Ambidexterity and performance in small-to medium-sized firms: The pivotal role of top management team behavioral integration. Journal of Management, 32(5), 646-672.

Luthans, F. (2002). The need for and meaning of positive organizational behavior, Journal of Organizational Behavior, 23(6), 695-706.

Luthans, F., Avolio, B. J., Avey, J. B., \& Norman, S. M. (2007). Positive psychological capital: Measurement and relationship with performance and satisfaction. Personnel Psychology, 60(3), 541572.

Luthar, S. S., Cicchetti, D., \& Becker, B. (2000). The construct of resilience: A critical evaluation and guidelines for future work, Child Development, 71(3), 543.

Manyena, S. B. (2014). Disaster resilience: A question of 'multiple faces' and 'multiple spaces'?. International Journal of Disaster Risk Reduction, 8, 1-9.

Marescaux, E., De Winne, S., \& Sels, L. (2013). HR practices and HRM outcomes: The role of basic need satisfaction. Personnel Review, 42(1), 4-27.

Masarik, A. S., Martin, M. J., Ferrer, E., Lorenz, F. O., Conger, K. J., \& Conger, R. D. (2015). Couple resilience to economic pressure over time and across generations. Journal of Marriage and Family, in-press.

Masten, A. (2001) Ordinary Magic: Resilience Processes in Development. American Psychologist. March.

McCray, J., Palmer, A. \& Chmiel, N. (2016). Building resilience in health and social care teams. Personnel Review, 45(6), 1132-1155.

McLarnon, M. J. W. and Rothstein, M. G. (2013). Development and initial validation of the workplace resilience inventory, Journal of Personnel Psychology, 12(2), 63-73.

Menguc, B. and Auh, S. (2008). The asymmetric moderating role of market orientation on the ambidexterity-firm performance relationship for prospectors and defenders. Industrial Marketing Management, 37(4), 455-470.

Mom, T. J., Fourné, S. P., \& Jansen, J. J. (2015). Managers’ work experience, ambidexterity, and performance: The contingency role of the work context. Human Resource Management, 54(S1), s133s153.

Newman, A., Ucbasaran, D., Zhu, F. and Hirst, G. (2014). Psychological capital: A review and synthesis, Journal of Organizational Behavior, 35(S1), S120-S138.

O'Brien, E., \& Linehan, C. (2014). A balancing act: Emotional challenges in the HR role. Journal of Management Studies, 51(8), 1257-1285.

Ollier-Malaterre, A. (2010). Contributions of work-life and resilience initiatives to the individual/organization relationship, Human Relations, 63(1), 41-62. 
O’Reilly, C. A., III, Harreld, J. B., \& Tushman, M. L. (2009), OA: IBM and emerging business opportunities. California Management Review, 51(4), 75-99.

O Reilly, C. A., \& Tushman, M. L. (2004). The ambidextrous organization. Harvard Business Review, 82(4), 74-83.

O’Reilly III, C. A., Caldwell, D. F., Chatman, J. A., \& Doerr, B. (2014). The promise and problems of organizational culture: CEO personality, culture, and firm performance. Group \& Organization Management, 39(6), 595-625.

Pal, R., Torstensson, H., \& Mattila, H. (2014). Antecedents of organizational resilience in economic crises-an empirical study of Swedish textile and clothing SMEs. International Journal of Production Economics, 147, 410-428.

Panter-Brick, C., \& Leckman, J. F. (2013). Editorial commentary: resilience in child developmentinterconnected pathways to wellbeing. Journal of child psychology and psychiatry, 54(4), 333-336.

Papazoglou, K., \& Andersen, J. P. (2014). A guide to utilizing police training as a tool to promote resilience and improve health outcomes among police officers. Traumatology: An International Journal, 20(2), 103.

Patel, P. Messersmith and Leepak (2013) Walking the tightrope: An assessment of the relationship between high performance work systems and OA. Academy of Management Journal. 36(5): 14201442.

Peterson, C., and Park, N. (2006). Positive organizational scholarship. In Positives Management (pp. 11-31). Deutscher Universitätsverlag.

Price, C., \& Whiteley, A. (2014). Corporate Culture and Employee Identity: Co-option or Commitment through Contestation?. Journal of Change Management, 14(2), 210-235.

Prieto, I. M. and Pilar Pérez Santana, M. (2012), Building ambidexterity: The role of human resource practices in the performance of firms from Spain, Human Resource Management, 51: 189-211. doi: 10.1002/hrm.21463.

Purcell, J. (1987). Mapping management styles in employee relations. Journal of Management Studies, 24(5), 533-548.

Purcell, J., \& Gray, A. (1986). Corporate personnel departments and the management of industrial relations: two case studies in ambiguity. Journal of Management Studies,23(2), 205-223.

Quoidbach, J., Mikolajczak, M., \& Gross, J. J. (2015). Positive interventions: An emotion regulation perspective, Psychological Bulletin, 141(3), 655.

Raisch, S. and Birkinshaw, J. (2008), OA: Antecedents, outcomes, and moderators. Journal of Management 34 375-409.

Riad, S. and Vaara, E. (2011), 'Varieties of national metonymy in media accounts of international mergers and acquisitions.' Journal of Management Studies, 48 (4):pp.737-771.

Riad, S., Vaara, E. and Zhang, N. (2012), 'The intertextual production of international relations in mergers and acquisitions.' Organization Studies 33: 121-148. 
Robertson, I. T., Cooper, C. L., Sarkar, M., \& Curran, T. (2015) Resilience training in the workplace from 2003 to 2014: A systematic review, Journal of Occupational and Organizational Psychology, 88(3), 533-562.

Roisman, G. I. (2005). Conceptual clarifications in the study of resilience, The American Psychologist, 60(3), 264-265.

Schultz, C., \& van der Walt, H. (2015). Reinventing HR: Strategic and Organisational Relevance of the Human Resources Function. Knowres Publishing.

Seligman, M. (2011) Building Resilience. Harvard Business Review. April 100-109.

Seery, M. D., Holman, E. A. and Silver, R. C. (2010). Whatever does not kill us: Cumulative lifetime adversity, vulnerability, and resilience, Journal of Personality and Social Psychology, 99(6), 10251041.

Shaw, P. (2012) The Age of Agility. London, Praesta Partners.

Shin, J., Taylor, M. S., and Seo, M. (2012). Resources for change: The relationships of organizational inducements and psychological resilience to employees' attitudes and behaviors toward organizational change, The Academy of Management Journal, 55(3), 727-748.

Siggelkow, N. (2007), Persuasion with case studies. Academy of Management Journal, 50, pp. 20-24.

Silverman, D. (2011) Qualitative Research. London, Sage Publications.

Simsek, Z. (2009), OA: Towards a Multilevel Understanding. Journal of Management Studies, 46: 597-624. doi: 10.1111/j.1467-6486.2009.00828.x

Smith, S.M. (2016) 'Management and organization - the $21^{\text {st }}$ century global and international context'. In Stokes, P., Moore, N., Smith, S., Rowland, C. and Scott, P. Organizational Management: Approaches and Solutions. London: Kogan Page.

Southwick, S. M., Bonanno, G. A., Masten, A. S., Panter-Brick, C., \& Yehuda, R. (2014). Resilience definitions, theory, and challenges: interdisciplinary perspectives. European journal of psychotraumatology, 5.

Spicer, A., Alvesson, M., and Kärreman, D. (2009). Critical performativity: The unfinished business of critical management studies. Human Relations, 62(4), 537-560.

Spradley, J. (1980) Participant Observation, Belmont, Cengage Learning.

Stokes, P. (2007) 'The "Militarizing” of Organization and Management Studies: Reconnoitring the Tensions - Problems and Possibilities for Reshaping the Terrain?' in Stokes, P., Bishop, R and Phillips, J (eds) (2007) in the special Issue on 'Militarization and International Business Critical Perspectives on International Business, 3(1): 11-26.

Stokes, P. and Gabriel, Y. (2010), "Engaging with genocide - challenges for organization and management studies”, Organization, 17(4): 461-80.

Stokes, P. (2011). Critical Concepts in Management and Organization Studies, Basingstoke, Palgrave-Macmillan. 
Stokes, P., and Harris, P. (2012). Micro-moments, choice and responsibility in sustainable organizational change and transformation: The Janus dialectic. Journal of Organizational Change Management, 25(4), 595-611.

Stokes, P., Moore, N., Moss, D., Mathews, M., Smith, S.M., \& Liu, Y. (2015). The Micro-Dynamics of Intraorganizational and Individual Behavior and Their Role in Organizational Ambidextrous Boundaries. Human Resource Management, 54 (1), 63-86.

Stokes, P., Liu, Y., Smith, S., Leidner, S., Moore, N., \& Rowland, C. (2016). Managing talent across advanced and emerging economies: HR issues and challenges in a Sino-German strategic collaboration. The International Journal of Human Resource Management, 27(20): 2310-2338.

Stokes, P., Moore, N., Smith, S. M., Larson, M. J., \& Brindley, C. (2017). Organizational Ambidexterity and the Emerging-to-Advanced Economy Nexus: Cases from Private Higher Education Operators in the United Kingdom. Thunderbird International Business Review, 59(3), 333348.

Thomas, G. and Myers, K. (2015) The Anatomy of the Case Study. London, Sage.

Tsang, E. W. (2014). Generalizing from research findings: the merits of case studies. International Journal of Management Reviews, 16(4), 369-383.

Tugade, M and Frederickson, B. (2004). Resilient individuals use positive emotions to bounce back from negative emotional experiences. Journal of Personality and Social Psychology, 86(2): 320-333.

Tushmann, M. and O’Reilly, C. (1996) ambidextrous organizations: Managing evolutionary and revolutionary change. California Management Review. 38(4):8-30.

Tushmann, M. and O’Reilly, C. (1996), Ambidextrous organizations: Managing evolutionary and revolutionary change. California Management Review. 38(4):8-30.

Ungar, M. (2011). The social ecology of resilience: A handbook of theory and practice, London: Springer.

Ungar, M. and Liebenberg, L. (2011) Assessing Resilience Across Cultures Using Mixed Methods: Construction of the Child and Youth Resilience Measure, Journal of Mixed Methods Research, 5 (2), 126-149.

van den Bosch, R., \& Taris, T. W. (2014). The authentic worker's well-being and performance: The relationship between authenticity at work, well-being, and work outcomes. The Journal of Psychology, 148(6), 659-681.

van Doorn, R. R., \& Hülsheger, U. R. (2015). What makes employees resilient to job demands? The role of core self-evaluations in the relationship between job demands and strain reactions. European Journal of Work and Organizational Psychology, 24(1), 76-87.

Voss, G. B., and Voss, Z. G. (2013). Strategic ambidexterity in small and medium-sized enterprises: implementing exploration and exploitation in product and market domains. Organization Science, 24(5), 1459-1477.

Walklate, S., \& Mythen, G. (2014). Contradictions of Terrorism: Security, Risk and Resilience. Routledge. 
Wang, J., Cooke, F. L., \& Huang, W. (2014). How resilient is the (future) workforce in China? A study of the banking sector and implications for human resource development. Asia Pacific Journal of Human Resources, 52(2), 132-154.

Watson, D. (2006). Death sentences: How clichés, weasel words and management-speak are strangling public language. Gotham.

Weick, K. (1995) Sensemaking in Organizations. London, England, Sage.

Werner, E. E., and Smith, R. S. (2001). Journeys from childhood to midlife: Risk, resilience, and recovery. Cornell University Press.

Willmott, H. and Seabrook, S. 2014. The rigor of management education and the relevance of human resource development - natural partners or uneasy bedfellows in management practice?. Management Learning 45(1), pp. 39-56.

Willmott, H. 2013. 'The substitution of one piece of nonsense for another': Reflections on resistance, gaming, and subjugation. Journal of Management Studies 50(3), pp. 443-473.

Wilson, S. M., and Ferch, S. R. (2005). Enhancing resilience in the workplace through the practice of caring relationships. Organization Development Journal. 23(4), 45.

Wood, S., \& de Menezes, L. M. (2011). High involvement management, high-performance work systems and well-being. The International Journal of Human Resource Management, 22(7), 15861610.

Xing, Y., Liu, Y., Tarba, S., \& Wood, G. (2016). A cultural inquiry into ambidexterity in supervisorsubordinate relationship. The International Journal of Human Resource Management, 1-29.

Yagil, D., \& Medler-Liraz, H. (2013). Moments of truth: Examining transient authenticity and identity in service encounters. Academy of Management Journal, 56(2), 473-497.

Youssef, C. M., and Luthans, F. (2007). Positive organizational behavior in the workplace the impact of hope, optimism, and resilience. Journal of Management, 33(5), 774-800. 